\title{
Las relaciones entre América Latina y Europa Occidental: los actores nacionales y transnacionales, sus objetivos y expectativas
}

América Latina se cuenta entre las regiones que "llegaron tarde" al sistema internacional. Hay razones imperativas para ello, que no es necesario enumerar aquí, siendo una de las más importantes el papel preponderante que EE. uU. juega en las relaciones exteriores de la mayoría de los estados latinoamericanos. Sin embargo, no cabe duda que, a comienzos de los años 80 , EE. UU. ya no se puede considerar como intermediario entre Latinoamérica y el resto del mundo. También es ocioso discutir el por qué fue justamente a fines de los años 70 que América Latina se convirtió en participante activo de la política internacional. Entre otros factores cabría citar a las exigencias económicas, la importancia creciente dentro del sistema internacional del Tercer Mundo en general, la resultante del cambio de peso específico de América Latina en la política internacional y por fin, la respuesta al incremento de interés en América Latina por parte de otros actores del sistema internacional. Estos son los factores que tienen que tomarse en cuenta como contribuyentes a un proceso cuyo fin aún no puede determinarse de ninguna manera.

Este análisis tiene por fin examinar hasta qué punto Europa Occidental es capaz de cumplir un papel relevante para ambas partes en el proceso de integración de América Latina al sistema internacional tanto a nivel de región como de estados individuales. No es mi propósito presentar un análisis económico, aunque se sobreentiende que en el conjunto de las relaciones internacionales las económicas no pueden ser pasadas por alto; mas quiero llamar la atención sobre el hecho de que tras varios decenios, ciertas afinidades políticas entre Europa Occidental y América Latina han caído en el olvido.

Ello sucedió en parte porque Europa Occidental estaba preocupada exclusivamente en sí misma, en parte también porque EE. UU. había desarrollado el concepto de "hemisferio occidental" hasta tal grado de exclusividad que no parecía dar cabida a otro plexo de relaciones estrechas.

Para evaluar las perspectivas de la cooperación entre América 
Latina y Europa, primero hay que aclarar la posición de las dos regiones en el contexto internacional, sus diferencias y características comunes, para entonces hacer comparación de sus expectativas. Por último este análisis tratará brevemente las perspectivas de desarrollo de las relaciones interregionales, así como las ventajas $y^{\prime}$ desventajas de una cooperación más estrecha, señalando también los obstáculos que en ambos lados impiden tal cooperación.

\section{La integración de América Latina al sistema internacional}

El cambio fundamental del rol latinoamericano en el sistema internacional es muy bien ilustrado si se comparan las reacciones latinoamericanas a la política de EE. Uu. en Guatemala en 1954, y 25 años más tarde, en Nicaragua en 1979. Sin necesidad de interpretar a lo largo las modificaciones del peso en el campo internacional de este período, queda precisado la transformación fundamental que acusó América Latina en su calidad de actor político a comienzos de los años 80. Tal vez más decisivo que atribuirlo al poder hegemónico debilitado de los EE. UU. o al fortalecimiento de la posición negociadora y de la influencia política de América Latina, es darse cuenta de que no se puede retrotraer a la situación de dos décadas atrás,

Durante la mayor parte de los treinta años que transcurrieron desde el inicio de la OEA, América Latina se ha encontrado inserta en el subsistema del "hemisferio occidental". El sistema interamericano dio lugar a roces, al mismo tiempo que proyectaba una "sombra de seguridad" para todos los estados latinos, incluso Cuba, que a pesar de salir del subsistema debe algo de su margen político internacional al hecho de que, geográficamente, sigue siendo parte cle él.

Este subsistema del "hemisferio occidental" sufrió no solamente la superposición, sino que en parte fue abolido por cuatro subsistemas nuevos a través de los cuales es que América Latina está efectuando su integración al sistema internacional. Estos subsistemas son los siguientes:

1. América Latina-Europa Occidental.

2. América Latina-Estados del Pacífico, con Japón como centro de gravedad.

3. América Latina-Africa y Cercano Oriente.

4. América Latina-Estados socialistas.

La participación o la integración, respectivamente, de América Latina, en estos cuatro subsistemas en su totalidad o por lo menos a nivel de estados individuales, no sustituye necesariamente al sub. sistema "hemisferio occidental" dominante hasta ahora. La impor- 
tancia dada a la participación en los varios subsistemas depende más bien de las prioridades establecidas por parte de los latinoamerícanos," sobre todo en el campo económico. Otro factor determinante para ello es, por cierto, la orientación política interna da los respectivos regimenes latinoamericanos. Dada la naturaleza del asunto, no es posible excluir la participación simultánea de los países de la región en varios subsistemas. Por otra parte, cuando se examina individualmente a los estados, resulta que los cambios de preferencia con respecto a los sistemas están sujetos a un ritmo coyuntural. Brasil es un buen ejemplo, pues habiendo concentrado sus intereses políticos y económicos en el subsistema. "América Latina-Europa Occidental" durante gran parte de los años 70, a comienzos de los años 80 está dando prioridad al subsistema "América Latina-Africa y Gercano Oriente" 1 .

La situáción geográfica y las necesidades específicas, tanto políticas como económicas de cada estado, no solamente hacen posible sino tämbién necesario seleccionar los subsistemas que deben ser considérados. Es evidente así que el carácter heterogéneo de América Latina se está acentuando; resulta lógico que, por ejemplo, México, Perú y Chile se dediquen más al sistema "América LatinaPacífico", mientras en el subsistema "América Latina-Africa y Cercano Oriente" participan más activamente Brasil, Argentina y Venezuela. Sin embargo, si se analiza la OPEP -aunque se trata de un caso muy extremo y especial- demuestra que subsistemas políticoeconómicos eficaces no tienen que limitarse forzosamente a las regiones geográficas donde normalmente tienen su centro de gravedad. Más bien es importante que existan como en el caso del subsistema "hemisferio occidental", características comunes a todos los participantes, tanto con respecto a las exigencias de alianza como frente a otros actores de la jerarquía internacional.

El hecho de que América Latina fue capaz de integrarse a los nuevos subsistemas y contribuir a su formación, indica claramente que, siendo más activa a varios niveles y más competente en su política exterior desde los años 70 , se ve ahora en condiciones de defender sus intereses en muchos "frentes" e impedir que se le pase por alto en los esfuerzos por reestructurar el sistema internacional2.

No parece coincidencia el paralelismo que es posible establecer entre América Latina y Europa Occidental con respecto a la participación simultánea en varios subsistemas. Parecido al del "hemisferio occidental" -aunque menos exclusivo- el subsistema "Atlántico" durante muchos decenios constituía el factor dominante de la

${ }^{1}$ Véase Wolf Grabendorff, La Política Exterior del Brasil entre el Primer y Tercer Mundo, en Nueva Sociedad, No 41, marzo/abril 1979, pp. 108-119.

"Véase para una discusión detallada, Marcelo E. Aftalión, Poder Negociador Latinoamericano; en Foro Internacional, Vol. 15, No 4 (abril-junio 1975), páginas 536-562. 
política internacional europea. Entre tanto, sin embargo, otros subsistemas entraron en la política internacional de Europa Occidental, como por ejemplo "Europa Occidental-Cuenca del Mediterráneo", "Europa Occidental-Estados Arabes", "Europa Occidental Asociación de Naciones del Sudeste Asiático", y particularmente "Europa Occidental-Estados Socialistas".

Tanto para los europeos como para los latinos, ha sido y todavía es bastante arduo el proceso de desprendimiento, es decir, el cambio de criterios en cuestiones de soberanfa del subsistema hasta entonces dominante hacia nuevos subsistemas aún inestables y cuyo desarrollo a largo plazo no puede ser pronosticado. La transferencia de estructuras transnacionales de un sistema a otro es particularmente lenta y difícil, pues a veces se hace necesario un cambio de élites o de generación. Por ello resuita que las comparaciones entre las ventajas de participar en uno u otro subsistema tienen muy poca aplicabilidad. Es obvio que toda diversificación de relaciones exteriores, todo cambio de preferencia tiene que pagarse con ciertas desventajas en el contexto prevaleciente hasta entonces. También hay que contar con los obstáculos puestos intencionalmente por la potencia dominante, es decir EE. UU., para impedir que Europa Occidental o América Latina "salgan de la fila".

Al mismo tiempo, y a pesar de todos los retrocesos experimentados, la diversificación crecıente de las relaciones exteriores aporta a los actores latinoamericanos un aumento de independencia, que a su vez casi automáticamente contribuye a precipitar el proceso de emancipación. Ello tiene que ver, y no en último lugar, con el hecho de que para América Latina la política exterior siempre ha sido una especie de estrategia de sobrevivencia, y que en la mayoría de los estados latinoamericanos, el progreso no podía ser estrmulado sino por intermedio de poderosos socios extranjeros. Quiere decir que la asimetría experimentada en la estructura de las relaciones internacionales enseñó a América Latina a evitar presiones causadas por un enlace demasiado estrecho con una u otra superpotencia o sistema económico, diversificando sus relaciones.

Me parece que el problema específico de América Latina consiste en que su integración al mercado mundial tuvo lugar mucho antes de su integración al sistema mundial. Por ello sus esfuerzos por conciliar su integración en el campo político y económico mundial son de tan extraordinaria importancia y al mismo tiempo tan comprensibles. Solamente la capacidad latinoamericana de establecer continuamente nuevas alianzas, como los subsistemas aquí descritos, puede garantizar que las clásicas relaciones Norte-Sur serán sustituidas finalmente por una red multipolar de interdependencia, a diferentes niveles. 


\section{Caracteristicas del subsistema América Latina-Europa Occidental}

La formación del subsistema América Latina-Europa Occidental es un proceso que se inició mucho antes de mediados de los años 70. Las relaciones históricas y culturales no se han roto desde la era colonial, y a pesar de la influencia preponderante de EE. UU. en el campo político, económico y militar durante los últimos 30 años, algunas estructuras de interacción con Europa permanecieron activas, aunque tenían mayor relevancia en el marco de las relaciones bilaterales y transnácionales que en el contexto de la política interregional.

¿Cuáles son los elementos que las posiciones en el sistema internacional de las dos regiones tienen en común? Es de suponer que el mayor común denominador, es la vulnerabilidad frente a EE. UU., que vale tanto para América Latina en el sistema interamericano como para Europa Occidental en el sistema Atlántico. Las dos regiones, por razones históricas muy diferentes, terminaron por asumir un rol de socios menores de EE. UU. y en ambas el proceso de emancipación está acompañado por una sensación de vulnerabilidad-económica y particularmente en cuanto a la seguridad. Por lo tanto ni América Latina ni Europa en ninguna fase de su acercamiento mutuo han perdido de vista las eventuales reacciones por parte de la potencia hegemónica ${ }^{3}$. La preponderancia de la dimensión económica en sus relaciones, tan recalcada por los dos, se explica en parte por esa razón, pues las relaciones comerciales entre Europa Occidental y América Latina resultaban funcionales a los propósitos de EE. Uu., mientras que las vinculaciones políticas o, tal vez, de seguridad no se toleraban en absoluto, (factor que también explica la elevada sensibilidad de EE. uo. frente a las iniciativas europeas en América Central). Es obvio que la idea de potencias de segundo orden (como Francia y México) tomando iniciativas contrarias a los objetivos globales y la percepción de seguridad de EE. UU. no puede quedar sin repercusiones en los subsistemas hasta ahora dominantes, a saber EE. UU.-América Latina y EE. UU.-Europa Occidental.

Hasta el presente, EE. vu. habia considerado ambas regiones como económicamente importantes y poseedores de extraordinario potencial, pero de menos relevancia en el campo político (algo que los dos tienen en común, así como una estructura bastante coope-

'Véase Wolf Grabendorff, The United States and Western Europe: Competition or Cooperation in Latin America? Trabajo presentado a la conferencia internacional "A New Atlantic Triangle? Latin America, Western Europe and the United States", realizado en Brasilia del 15 al 17 de junio de 1981. Tambićn Roberto Aliboni, Europe and Latin America: Towards a Non-Especial Relationship, en Lo Spettatore Internazionale, Vol. 8, No 3 (julio-septiembre 1978), páginas $179-197$. 
rativa a nivel regional). Al contrario del sistema regional de los estados árabes, por ejemplo, América Latina y Europa no se orientan hacia un conflicto sino que, aunque en grado diferente, muestran una disposición para vivir lado a lado con reinos y potencias de variada índole ideológica. No obstante la generalización que necesariamente implica tal afirmación, esto podría contar como un fuerte elemento en favor del subsistema América Latina-Europa Occidental, si fuera capaz de seguir desarrollando este factor común $y$ de hacerlo prevalecer en los conflictos internacionales.

En resumen, se percibe claramente un eje de empuje hacia la emancipación de las potencias de segundo orden. Sin embargo, fue únicamente la pérdida de influencia de EE.UU. como potencia hegemónica que hizo posible que las dos regiones se convirtieran en centros de poder en cierta medida independientes. Por eso, el interés común de las dos regiones se halla en reducir lo más posible la influencia de las superpotencias a nivel mundial, pues solamente bajo tal premisa es posible extender el margen político internacional, sea actuando conjunta o individualmente.

Contraponiendo estas características comunes a las graves diferencias entre las dos regiones a nivel internacional, queda claro que es aquí la diferencia entre Primer y Tercer Mundo la más destacada. Aunque no cabe duda de que América Latina constituye hoy en día la parte mejor desarrollada del Tercer Mundo, y aunque aún no está suficientemente aclarado si América Latina debe ser considerada como parte del Tercer Mundo o como una especie de "clase media" en el sistema internacional", naturalmente existe una disensión fundamental entre las dos regiones, caracterizada por la tensión entre los que defienden y los que buscan prestigio en la jerarquía internacional. Que América Latina en los últimos años ya obtuvo y seguirá sacando provecho del cambio de peso a favor del Tercer Mundo, es más bien un factor secundario. Más importante es que la identidad política europea está influida por las experiencias del conflicto Este-Oeste y que por consiguiente no está consciente del conflicto Norte-Sur como lo está América Latina. Por supuesto, lo mismo es válido "mutatis mutandis" para América Latina.

Pero tales diferencias fundamentales se nivelarán a fines de los años 80, con la superposición del conflicto Este-Oeste por el conflicto Norte-Sur y la inclusión progresiva clel Tercer Mundo en la polarización entre el Este y el Oeste.

La concepción corriente en el Primer Mundo que percibe en el Tercer Mundo un riesgo de seguridad o un mercado económico farorable, es decir una oportunidad de sacar beneficios ${ }^{5}$, está elimina-

tVéase Francisco Orrego Vicuña (ed.), América Latina: Clase Media de las Naciones. Santiago de Chile 1978.

'Para una critica de esta concepción véase Claude Cheysson, Security and 
da en medida creciente por la noción de que la integración incipiente de América Latina al sistema internacional lleva consigo la necesidad de participar más en las decisiones a nivel internacional. Otra diferencia es que Europa Occidental es mucho más vulnerable en materia de seguridad que América Latina. Al lado del mundo árabe. Europa Occidental sigue siendo el foco del conflicto entre las superpotencias y al mismo tiempo la parte del mundo en la que cada potencia trata de abrir paso a su ideología

En consecuencia, la vista pluralista europea de ciertos acontecimientos internacionales tiene que contrastar con la visión más aislada de los latinoamericanos.

Sin embargo, esta diferencia también desaparecerá al cabo de los años, a medida que América Latina, por su participación en subsistemas como los mencionados arriba, globalizará sus relaciones exteriores. Por otra parte, si los pronósticos son correctos, en los próximos años surgirá otra diferencia y es que la cuota latinoamericana en la producción mundial aumentará, mientras que la europea disminuirá proporcionalmente. Ello significa que las drásticas diferencias económicas tenderán a nivelarse, si uno toma el promedio estadístico y no la renta per cápita real. Tal tendencia, empero, no puede hacer olvidar que la totalidad de las diferencias sigue prevaleciendo con fuerza en el subsistema, y que por lo tanto éste se caracterizará por su asimetría en los años 80 .

\section{Las expectativas de los miembros del subsistema}

Sin exagerar demasiado, se puede afirmar que la forma actual del subsistema ha cumplido la mayor parte de las esperanzas europeas y frustrado la mayoría de las latinas. Aunque la "carta europea" ha dado buen resultado como instrumento para mantener la independencia y emancipación de la potencia hegemónica, los EE. UU., los latinoamericanos nunca han tenido la impresión de que los europeos hagan concesiones a los deseos latinoamericanos. Por lo menos en algunas partes de América Latina, Europa Occidental, todavía es considerada como representante de EE. UU., sin margen político propio, sobre todo en cuestiones de índole ideológica.

Muchos latinoamericanos, por cierto, están dispuestos a reconocer que Europa Occidental, como Japón, puede ofrecer oportunidades semejantes que EE. UU., en muchos campos, así se trate de créditos, de transferir tecnología o del acceso a los mercados, con la importante diferencia que los europeos no pueden vincularlas a cuestiones políticas. Lo que a menudo se toma muy mal, es que en el fondo los europeos no son capaces, o no están dispuestos a ofrecer

Development, A View from Europe, presentado en un seminario del Banco Mundial en Annapolis (Maryland), el 3 de abril de 1981. 
mejores condiciones, pues en la opinión de muchos latinoamericanos, las concesiones económicas europeas para América Latina resultan diametralmente opuestas a las soluciones políticas y sociales que en Europa se consideran oportunas para la región. En suma, en América Latina se critica que Europa Occidental esté tan integrada a la coalición de Estados altamente industrializados y tan dependientes de EE. UU. en su política exterior que - salvo algunas excepciones- América Latina no puede esperar mucho de los europeos cuando se trata de modificar el orden internacional, concepto que abarca más que el orden económico internacional.

No es realista, sin embargo, evaluar las esperanzas latinoamericanas a nivel tan general. Tomando en cuenta la enorme heterogeneidad de América Latina ${ }^{6}$ hay que distinguir cuatro tipos de actores o grupos latinoamericanos:

a) Los representantes regionales en el exterior, originalmente GEGLA, después los GRULA's de Nueva. York, Bruselas y Ginebra, y hoy, sobre todo el SELA.

b) Los países principales de América Latina como Brasil, México, Venezuela y Argentina.

c) Las potencias latinoamericanas medianas.

d) Los estados pequeños de América Latina.

Sólo a través de tal distinción es posible darse cuenta de las esperanzas latinoamericanas en su totalidad, para después confrontarlas a las europeas.

\section{a) América Latina como actor regional}

América Latina se queja de ser discriminado frente a la multitud de acuerdos de asociación y preferencia que Europa Occidental, a través de Ia Comunidad Europea, concluyó con una serie de países en vía de desarrollo". El deseo expresado en la célebre "Carta de Buenos Aires" (1970), de establecer un diálogo político y un acuerdo a largo plazo con Europa Occidental no ha podido realizarse has-

\footnotetext{
'Para esta heterogeneidad véase Wolf Grabendorff, Perspectivas y Polos de Desarrollo en América Latina, en Nueva Sociedad No 46, enero-febrero 1980 , pp. 39-53.

TPara una discusión crítica latinoamericana de la actitud europea y de la polftica de desarrollo seguida por las Comunidades Europeas, véase sobre todo Ios siguientes autores: Miguel S. Wionczek: Las Relaciones entre CEE y América Latina en el Contexto de una Crisis Económica Global, trabajo presentado en el Seminario sobre las Relaciones entre la Comunidad Económica Europea y América Latina. Bruselas, mayo de 1980; Blanca Muñiz, eEc-Latin America: A relationship to be defined, en Journal of Common Market Studies, Vol. 19, No 1 (September 1980), pp. 55-64; The Economic Relations of Latin America with Europe, Cuadernos de la Gepal, Santiago de Chile 1980. A Latin American Position. Torwards the EEC is Outlined. Analysis of Punta del Este, en SELA, en Acción, No 6, 1979, pp. 12-23.
} 
ta ahora. Una y otra vez se mencionó el "diálogo entre sordos", pero ni siquiera la exhortación repetida por SELA $(1978)^{8}$ ha sido capaz de obtener la conclusión de un tratado base para regular las relaciones mutuas. Las esperanzas del SELA y de América Latina como règión (poco realistas, porque Ios que dentro de la Comunidad abogarían por la asociación de América Latina no tienen peso político suficiente) están orientadas hacia Europa Occidental como región, siendo la Comunidad Europea el apostrofado. Por otra parte, América Latina tampoco supo procurarse más atención en Bruselas, a pesar de esporádicas tentativas de ejercer presión sobre la CEE. Y no fue Bruselas sino el Parlamento europeo el primero en comprender que un aumento de las relaciones políticas entre Europa Occidental $y^{r}$ América Latina era inevitable 9 . Eso significa que tal vez ahora, por primera vez, los deseos latinoamericanos encontrarán oídos mejor dispuestos.

\section{b) Los principales paises latinoamericanos}

Estos polos de desarrollo defienden intereses en parte parecidos, en parte opuestos a los de la región. Los cuatro estados-Brasil, México, Venezuela y Argentina- están resueltos a realizar la integración al sistema internacional más a nivel nacional que regional10, aunque no de manera exclusiva, lo que implica que se preocupan muchísimo por el estado de las relaciones con Europa Occidental. Los criterios que forman la base de las relaciones bilaterales (no sólo con Europa Occidental), son los siguientes: Las contrapartes tienen que ofrecer acceso a:

- un mercado grande y diverso

- materias primas

- recursos financieros

- tecnología moderna.

Ni siquiera México y Venezuela, dos países exportadores de petróleo, pueden privarse del acceso a recursos financieros, y en consecuencia muy pocos estados en el mundo entraban en consideración suficientemente estrecha, junto con EE. vU. y Japón, tenía que ser considerada en primer lugar Europa Occidental. Por sus enormes posibilidades económicas, los países principales de América Latina tienen una posición extremadamente fuerte frente a Europa Occidental. Las negociaciones del contrato nuclear brasileño-ale-

Informe Final de la Reunión de Consulta sobre las Relaciones de América Latina con la Comunidad Económica Europea. SELA, RC/AL-GEE/r/DF, No 2, 24 de noviembre de 1978; Capítulos II y III publicados en Integración Latinoamericana, Año 4, No 33 (marzo 1979), pp. 57-63.

'Véase los documentos de la Quinta Conferencia Interparlamentaria EuropaAmérica Latina, en Bogotá, enero de 1981.

${ }^{10}$ Véase Grabendorff, Perspectivas y polos de desarrollo, op. cit. 
mán, en los que incluso se logró instrumentar a algunos países industrializados contra otros en la distribución de las órdenes de compra importantes, es buen ejemplo de ello. Aunque por razones históricas y geopolíticas las relaciones de Brasil y Argentina, a diferencia de Mréxico y Venezuela, se extendiexon mucho en el último decenio, no significa que automáticamente verán sus deseos cumplidos por Europa Occidental en el futuro11. Muy por el contrario, la rápida industrialización que experimentaron y la necesidad de competir con los productos de las industrias europeas en el mercado mundial más bien llevan consigo un deterioro de las relaciones político-económicas. Todas las potencias principales, con excepción de Venezuela, tienen acuerdos individuales con la Comunidad Europea. Los tres países no están muy entusiasmados por los resultados de estos acuerdos; por ello y debido al aumento de su peso político internacional, tienen más interés en incrementar las relaciones bilaterales con los estados europeos de alguna importancia.

\section{c) Las potencias latinoamericanas medianas}

EI grupo constituido por Chile, Perú, Colombia, Ecuador y otros países, hasta ahora no ha podido arriesgar una "jugada individual" hacia Europa Occidental. Siempre ha demostrado mucho interés en relaciones más estrechas entre los mecanismos de integración subregionales, sobre todo entre el Pacto Andino y la Comunidad Europea12. Las perspectivas de los últimos años tampoco fueron malas, pero en razón de la situación político boliviana por el momento se hallan atravesando un campo de espera. Lo que estos estados desean de Europa Occidental tiene que ver más con su política de desarrollo que con la política comercial. Por su limitada capacidad económica, el "polo europeo" tiene muy poca importancia con ellos, resultando muy reducidas sus posibilidades de diversificar las relaciones exteriores.

\section{d) Los pequeños estados latinoamericanos}

Hay que entender que los estados de casi toda la cuenca de Centroamérica o del Caribe -por sus condiciones político-económicasse interesan sobre todo por obtener mejores relaciones con Europa Occidental en el campo del desarrollo. Para ellos, la integración a un sistema de tipo Lomé, sería satisfactorio, por lo menos parcial-

\footnotetext{
${ }^{11 E l}$ ejemplo típico es Brasil; véase Wolf Grabendorff, Brazil and West Germany: A Model for First World-Third World Relations? en: Wayne A. Selcher (Ed.), Brazil in the International System: The Rise of a Middle Power, Boulder/Col. 1981, pp. 181-200.

${ }^{2} \mathrm{La}$ primera reunión a nivel de ministros se celebró en Bruselas el 5 de mayo de 1980; véase Las relaciones entre Pacto Anclino y la CEE, en Integración Latinoamericana, Año 5, No 48 (Julio 1980), pp. 61-62.
} 
mente ${ }^{13}$. Pero no hay que esperar grandes iniciativas de su parte dentro del subsistema, pues en razón de su situación geopolítica la mayoría de ellos se halla muy estrechamente vinculada a EE. UU. como potencia hegemónica. Es solamente cuando tratan -como lo hicieron Nicaragua y Grenada- de apartarse de la influencia hegemónica a consecuencia de un cambio de régimen interno, que Europa se convierte en contraparte primordialit. No obstante, queda por comprobar hasta qué punto es posible un consenso entre gobiernos expresamente antinorteamericanos y los países europeos.

¿Cuáles son, pues, las esperanzas europeas frente al subsistema? En los últimos treinta años, los europeos no han sido muy concientes de los problemas latinoamericanos. Recién solamente el ascenso de las potencias principales, con su política exterior diversificada, puso a Europa en una posición más fuerte en el contexto latinoamericano. Tampoco se puede negar que con las situaciones conflictivas que presentan otras partes del Tercer Mundo, América Latina aparece como una promesa ante Europa, tan dependiente de energía y materias primas como es esta región. Desde el punto de vista europeo, América Latina, con sus 350 millones de habitantes, es el mercado más grande del Tercer Mundo, y mucho más diferenciado y receptivo de lo que son Asia, el Mundo Árabe o tal vez Africa. Además, América Latina tiene yacimientos minerales inexplotados y fabulosas reservas energéticas. Son atributos que siempre se ponen de relieve por ambas partes y que hicieron que la idea de las estructuras de producción complementarias pareciera más aceptable a Europa Occidental15. La discusión de una estrategia política de Europa Occidental frente a este nuevo coloso del Tercer Mundo está recién por empezar. Por el momento todavía no se tienen ideas claras respecto a la posible integración de las relaciones económicas y culturales, hasta ahora bastante incoherentes y limitadas al nivel bilateral y transnacional, en un sistema interregional funcional. Frente a la "estable inestabilidad" de los regímenes latinoamericanos, Europa ha tratado en general de evitar la definición de relaciones a nivel político y tanto más, como que el pluralismo de las sociedades europeas deja amplio espacio para actitudes divergentes para con América Latina. Los grupos más conservadores están mejor dispuestos a apoyar la imposición de "orden y justicia" por regímenes autoritarios, pues lo consideran como precon-

\footnotetext{
${ }^{13}$ Respecto al impacto para el Caribe véase Hans-Jörg Geiser, La Convención de Lomé y la Integración del Caribe: Una primera evaluación, en Integración Latinoamericana, Año 1, № 3 (junio 1976), pp. 31-47.

${ }^{14}$ Las discusiones entre Europa Occidental y EE. UU. sobre ayuda a América Central pueden servir como buen ejemplo de la importancia política de la "conexión europea".

${ }^{16}$ Véase Francisco Orrego Vicuña, Europa y América Latina: ¿Hacia un Rol Internacional Complementario?, en Estudios Internacionales, Año 14, No 53 (enero-marzo 1981), pp. 3-16.
} 
Wolf Grabendorff / Las relaciones entre América Latiua y Euxopa Occidental: ...

dición del crecimiento económico, mientras que los grupos progresistas consideran los cambios sociales como única báse de una estrategia de desarrollo a largo plazo. La consecuencia es que en Europa, América Latina está adquiriendo fama de terreno de experiencias políticas, sociales y económicas.

Esto, entre otras cosas, explica que, mientras las relaciones a nivel subestatal de los actores transnacionales ganaron en intensidad, Ias relaciones políticas a nivel estatal siempre mantenían un carácter muy formal. La cooperación de los partidos políticos, por cierto, fue la más conocida, pero los sindicatos, las iglesias, y una serie de intereses e instituciones científicas contribuyeron a lo que en América Latina hoy en día se llama la "conexión europea".

Sin duda los europeos, por su disposición a transferir recursos tanto humanos como materiales en apoyo de los intereses políticos y/o sociales de sus contrapartes latinoamericanas, coadyuvaron al fortalecimiento de las élites civiles en muchos países latinoamericanos, y en Europa esto se ve conscientemente como un correctivo del apoyo que los EE. UU. han dado a las élites militares. Ambos lados ponen bastante expectativa en los elementos transnacionales del subsistema. En la perspectiva europea existe ahí una oportunidad de dar apoyo a entes capaces de iniciar un cambio en sistemas políticos anticuados. Se fortifica al mismo tiempo la capacidad democrática de los países respectivos, bajo la perspectiva de familiarizar a los grupos apoyados con la concepción pluralista de la filosofía política europea.

'Claro está que en Europa tampoco puede hacerse caso omiso de que las élites en el poder de los respectivos países consideran esta manera de tomar partido, como intervención en los asuntos internos del país y por lo tanto, como característica muy negativa de las relaciones entre Europa Occidental y América Latina.

Aquf también es oportuno distinguir entre Ias esperanzas de Europa Occidental:

- como actor regional (Comunidad Europea)

- como actor demócratacristiano

- como actor socialdemócrata

- como actores nacionales (Francia, RFA, España).

Son las diferencias de percepción de estos actores las que aclaran la imagen difusa de las relaciones europeas con América Latina.

\section{a) Eunopa Occidental como actor regional (Comunidad Europea)}

Sin duda es correcto lo que se está afirmando: que en tanto la integración europea sirvió de modelo para América Latina, Europa Occidental se considera a sí misma como modelo para otras regiones. Pero en el caso latinoamericano surgieron en forma extremadamente nítida las repercusiones de la integración con terceros países: 
- En el proteccionismo inherente a toda comunidad económica (el mejor ejemplo es el reglamento del mercado agrario),

- En las preferencias por algunas regiones del Tercer Mundo en virtud de vínculos coloniales -sobre todo en Asia y África-que tiene por consecuencia la discriminación de otros países en vía de desarrollo,

- En la armonización de la política comercial externa de los miembros de la comunidad, que prácticamente hace imposible intervenciones políticas en el comercio exterior a nivel bilateral.

No obstante varias tentativas realizadas en los últimos años, la cooperación interregional con América Latina, según el modelo, por ejemplo del subsistema Europa Occidental-ASEAN, hasta ahora no ha tenido éxito. A diferencia del diálogo europeo-árabe, y de las relaciones con los países mediterráneos, América Latina no ha figurado en las cuestiones de seguridad dentro de la política exterior y comercial de la Comunidad. Además, la consideración a los intereses de EE. UU. hasta el momento hizo desistir a la Comunidad de tomar pasos hacia un tratado global de Asociación o Cooperación con América Latina, porque tenía conciencia de los imprevisibles efectos políticos que podía producir un tratado como el deseado por América Latina. Europa Occidental no podfa justificar este tipo de contrato con EE. UU. y pertenece obviamente al instrumental de las autoriclades en Bruselas el pensar en categorías de zonas de influencia regionales. Desde su punto de vista, la Comunidad siempre ha salido bastante bien parada, adoptando una política esquiva de apaciguamiento.

Fue posible para Europa llevar a cabo su estrategia de arreglarse con las potencias principales de América Latina, evitando en general pronunciarse sobre preferencias regionales, porque América Latina hasta el momento no se ha mostrado capaz de negociar con Bruselas en bloque y con suficiente capacidad de presión. Las iniciativas del SELA tampoco pudieron remediar esta situación, pues se encuentran continuamente contrariadas por la política de Brasil y Argentina frente al sistema económico latinoamericano.

\section{b) Europa Occidental como actor democratacristiano}

Las telaciones ideológicas con América Latina fueron iniciadas por los democratacristianos. Y poco después de la Segunda Guerra Mundial algunos filósofos católicos de Europa Occidental influenciaron en medida extraordinaria a intelectuales latinoamericanos a través de la doctrina social católica.

Eduardo Frei, desde comienzos de los años 60 la llevó a la práctica política en Chile bajo el nombre de "Revolución en Libertad" y fue sucedido por Rafael Caldera en Venezuela, una de las principales personalidades democratacristianas en América Latina desde 
fines de los años $60^{16}$ Es verdad, sin embargo, que a consecuencia del éxito electoral de Allende en Chile, por cierto periodo fueron considerados como "Movimiento Kerensky" y perdieron la benevolencia de la potencia hegemónica. Sin embargo, el apoyo de la democracia cristiana en la lucha contra los movimientos socialistas y marxistas, especialmente en América Central, coincide con los propósitos de los EE. UU. El movimiento democratacristiano mundial, basado principalmente en los partidos de Europa Occidental y América Latina, juega un papel importante en la crisis de El Salvador por su apoyo a Duarte17, aunque sería erróneo considerar tal actitud de la democracia cristiana europea hacia America Latina como típica. La mayoría de los democratacristianos europeos de ningún modo respaldan la política regional de EE. UU., aunque la afinidad de la democracia cristiana a la política de EE. UU. es más grande que la de los socialdemócratas, cuando se trata de dejar los movimientos marxistas fuera del juego político.

En general, se puede decir, sin embargo, que la concepción democratacristiana de los especificos problemas latinoamericanos es mucho más diferenciada, que la que se encuentra en EE. UU. Esto se explica, entre otras cosas, por el hecho de que el punto de vista ideológico y político de los particlos latinoamericanos generalmente es más de izquierda que el de los partidos europeos, es decir, que la gama ideológica del morimiento es extendida por los latinoamericanos.

Las esperanzas democratacristianas se pueden resumir ast:

Es imposible lograr la estabilidad política en América Latina bajo el signo norteamericano; lo que hay que evitar, de todas maneras, es un aumento de poder de los países socialistas o comunistas. Por consiguiente, lo más oportuno sería que los democratacristianos perpetren estas tareas, pues así los intereses occidentales se garantizarían, y también cabrian iniciativas latinoamericanas.

Esta idea de organizar una tercera fuerza política constituye un elemento integral de todas las expectativas de la democracia cristiana europea frente al continente.

\section{c) Europa Occidental aomo actor socialdemócrata}

Desde la segunda mitad de los años 70, especialmente desde el Congreso de la Internacional Socialista en Génova en 1976, la influen. cia del movimiento socialdemócrata ha aumentado considerablemen-

${ }^{10}$ Las obras de ambos reflejan en lo mejor la ideología democratacristiana: Rafael Caldera, La Democracia Cristiana en América Latina, Barcelona 1970; Eduardo Frei, América Latina: Opción y' Esperanza, Barcelona, 1977.

17Véase Mario Solorzano, El papel de la Democracia Cristiana en la actual coyuntura centroamericana, en Nueva Sociedad, Ni 48 (mayo-junio 1980), pp. 22.33 y Karl-Ludolph Hübener, Us-Administration + Christian Democrats $=$ Salvadorean Junta, en Socialist Affairs, No 6, diciembre 1981, pp, 215-220. 
te. Se trata, entre otras cosas, de una consecuencia de la importancia creciente del Tercer Mundo en la política internacional, pues el peso político de la Internacional Socialista - basada, como los democratacristianos, en los partidos europeos y latinos-, se incrementó al mismo tiempo que se abrió al T'ercer Mundo recibiendo nuevos impulsos, especialmente los de América Latina ${ }^{18}$. La is y los partidos socialdemócratas europeos en general parten de la premisa fundamental de que un Nuevo Orden Internacional no puede limitarse a la modificación de la economía mundial sino que la política de poder en el sistema internacional tiene que sustituirse por una orientación más participativa. Con razón éste fue considerado como un tercer camino entre idealismo y realismo político.

Por otro lado, especialmente con los sociademócratas media un abismo entre las pretensiones y la realidad, porque el interés del partido en una cooperación más estrecha con las contrapartes latinoamericanas no siempre tiene efectos en la política exterior del estado europeo respectivo, incluso cuando el Partido Social Demócrata está en el poder.

El problema de las esperanzas socialdemócratas consiste, entre otras cosas, en que por definición son eurocéntricos y emplean a América Latina como campo de experimentos de su política exterior progresista, y hasta a veces marxista (por consideración a su ala izquierda). El mérito de hacer prevalecer el estado social y la democracia económica ante el capitalismo conservador (modelo Reagan o Thatcher) ha investido a la Is de cierta aureola legendaria en América Latina, aunque parece que función primaria que se le atribuye es la de frenar abusos que cometen los EE. uU. en defensa de sus propios intereses como superpotencia. Por ejemplo, la is insistió en 1978 en Santo Domingo en que Carter hiciera que los militares respetaran las elecciones, sometió una solución para el problema de Nicaragua en 1979, y en 1980 por lo menos estableció una plataforma para discutir la solución política de la crisis de El Salvador. Dado el enorme carisma a nivel internacional de su Presidente Brandt y el éxito de sus acciones, más bien existe el peligro por la parte europea ( $y$ tal vez más todavía por la latina) que se le atribuya demasiado peso a la influencia de la Is, A las iniciativas socialdemócratas espera la suerte de las democratacristianas, que ya perdieron mucho de su pujanza.

\section{d) Europa Occidemtal como actores nacionales}

Giertamente hay que asignar la debida importancia al hecho de que algunos estados europeos siempre trataron de dar especial relieve a sus relaciones con América Latina. Entre ellos cuenta Italia

\footnotetext{
15Véase Michael Löwy, Trayectoria de la Internacional Socialista en América Latina, en Cuadernos Politicos, No 29 (julio-septiembre 1981), pp. 36-45, también Perspectivas del socialismo democrático en América Latina $y$ el Caribe, en Nueva Sociedad. No 48 (mayo-junio 1980), pp. 110-164.
} 
y últimamente, también Francia y la RFA. Además, hay que tener en cuenta el papel particular que juega España, quien pretende ser cabeza de puente, aunque aún no es miembro de la Comunidad Europea.

Ya en la era De Gaulle, Francia subrayaba la latinidad que tiene en común con los países latinoamericanos, tratando de jugar un papel especial en las relaciones entre Europa Occidental y América Latina. En ello, no en último lugar, existía la intención de acentuar su independencia de EE. Uu. Después de la elección de Mitterand se crea una nueva situación, porque evidentemente se está ensayando una política de izquierdas frente a América Latina. Y más todavía, como se trata de adquirir un perfil "antimperialista" sin arriesgar por eso importantes intereses económicos de Francia en América Latina, cosa que se logra, por ejemplo, mediante una opinión conforme a la posición mexicana sobre las cuestiones y probicmas de América Central. Esta importancia reciente de México está ensombreciendo las relaciones tradicionales con Perú, Argentina y' Brasil, fundamentados, entre otras cosas, en el comercio de armas. La doctrina del Ministro de Relaciones Exteriores francés Cheysson, de que Argelia, India y México hoy son las principales potencias del Tercer Mundo, indica que los intereses comunes de Francia con este país superan con mucho la iniciativa en favor de la oposición salvadoreña19. También fue la causa de que el rechazo de esta iniciativa por una multitud de estados latinoamericanos, tanto autoritarios como demócratas, no hirió gravemente a los franceses. Que Mitterand se declaró partidario de los "perdidos de la tierra" dio lugar a cierta confusión no solamente en América Latina sino también en Europa. Francia espera que los desenvolvimientos políticos en América Latina confirmen su concepción de que las potencias medianas del Tercer Mundo tomarán parte en mayor medida en las decisiones a nivel internacional, y espera ser el precursor de tal desarrollo emancipativo en América Latina.

Las iniciativas de la RFA hacia América Latina son mucho más modestas, comparado con las francesas ${ }^{20}$. El nivel de tolerancia hacia nuevos modelos de desarrollo en el Tercer Mundo generalmente siempre ha sido mucho más elevado que, por ejemplo, en EE. UU. En la RFA hubo por eso una gran cantidad de partidarios tanto del tipo de desarrollo de Perú bajo Velasco, como de Chile bajo Allende, y últimamente de Nicaragua. Por otra parte, en las iniciativas a nivel estatal siempre se ha actuado prudentemente respecto a la

\footnotetext{
I'Véase Dominique Moisi, Mitterands' Foreing Policy. The Limits of Continuity, en Foreign Affairs (Winter 1981/82), pp. 347-357.

${ }^{20}$ Véase Manfred Nitsch, Los intereses de los países ricos y el desarrollo del Tercer Mundo: La República Federal de Alemania, en Estudios Internacionales, Año 14, No 54 (abril-junio 1981), pp. 224-253 y también Manfred Mols, Las relaciones de la República Federal de Alemania con América Latina, en cPU-Estudios Sociales, No 27, 1981, pp. 29-53.
} 
política estadounidense en América Latina, al contrario de las actividades de algunos partidos. El caso de América Central y del Caribe ha demostrado claramente en los meses pasados que las relaciones entre la RFA y EE. UU., así y todo delicadas desde la asunción del mando de Reagan - no aguantan ulteriores factores irritantes. Ya con ocasión del tratado nuclear brasileño-alemán se echó de ver con nítida claridad el reducido margen político que tiene la RFA; a pesar de sus amplias posibilidades políticas en América Latina. Seguramente no es erróneo suponer que solamente en casos importantísimos y muy decisivos, se mostraría dispuesta a correr con los costos políticos para hacer concesiones a los latinoamericanos, aunque la RFA en especial hace esfuerzos para mantener a las grandes potencias fuera de las situaciones conflictivas del Tercer Mundo y tortalecer la emancipación y la independencia de los estados que forman parte de este último. Tanto en la crisis del Mediano Oriente como en la cle Africa del Sur, la RFA prefirió de manera inequívoca la solución regional a la global. Lo que se intenta poner en práctica como políticas para América Central y el Caribe sigue siendo el mismo criterio, pero teniéndose en cuenta las sensibiliclades específicas de Ee. vu., no se declara tan abiertamente.

Los perfiles nacionales de las relaciones Europa Occidental-América Latina no estarían completos sin la adición de España.

Desde su democratización, España siempre hizo resaltar su posición de puente entre Europa Occidental y América Latina. No obstante, es muy improbable que España, incluso después de su ingreso a la Comunidad Europea, que aún no tiene fecha puesta, posee la pujanza económica como para iniciar una revisión de la política comercial exterior de la Comunidad en favor de América Latina. $A$ este respecto, las grandes expectativas de algunos -aunque no de todos- países latinoamericanos por el ingreso de España a la Comunidad son desacertadas. Muy al contrario, el ingreso de España como país en parte inclustrializado, con un sector agrario importante, probablemente significará más competencia para los productos latinoamericanos en el mercado de la Comunidad. No quiere decir, sin embargo, que el aporte de España al subsistema América LatinaEuropa Occidental no puede ser muy importante en el campo cultural, y también en el político, pues sus vínculos históricos, y su elevada sensibilidad, en comparación con otros estados de la Comunidad Europea, la ponen en mejores condiciones de comprencler desarrollos políticos en América Latina e inducir una mejor disposición a concesiones por parte de Europa Occidental.

\section{Perspectivas para el desarrollo del subsistema}

Las perspectivas del subsistema América Latina-Europa Occidental para los años 80 no pueden ser calificados de ninguna manera como malas, a pesar de las diferentes expectativas y posibilidades de 
las dos regiones participantes. Mas en este contexto hay que llamar la atención sobre dos factores importantes para la cooperación a nivel interregional, a saber, el rol del estado y la estructura de las relaciones bilaterales.

El estado, como motor del desarrollo y correctivo de desfiguraciones en la estructura social causadas por el crecimiento económico es un concepto fundamentalmente europeo.

Tal rol del estado probablemente se extenderá en el futuro por: las nuevas interdependencias de la economía mundial. En la medida en que se formen nuevas relaciones contractuales entre diferentes regiones, será la tarea del estado no solamente la de servir como mecanismo de control y garante, sino también el tratar de compensar evoluciones internas exróneas provocadas por cambios estructurales en base a un nuevo orden económico mundial. Por lo tanto, el funcionamiento de nuevos subsistemas dentro del sistema internacional depende de manera decisiva de la calidad del estado como mecanismo de control eficaz. Como tal, el estado a largo plazo necesita ante todo la legitimación interna para realizar sus tareas. Desde el punto de vista europeo la instalación de democracias participativas en América Latina se hace indispensable. La forma específica que éstas adopten por supuesto tiene que quedar enteramente en manos de las sociedades latinoamericanas.

Al construir el subsistema América Latina-Europa Occidental, también es necesario disminuir las relaciones bilaterales, porque ahí la asimetría de las estructuras es más destacada.

Las relaciones bilaterales proporcionan a los estados industrializados ventajas unilaterales que en ciertos momentos permiten aplicar presiones políticas en las relaciones de intercambio. Códigos de conducta, por ejemplo, pueden establecerse como condición para las inversiones y ajuda al desarrollo, ( $y$ a veces las condiciones no tienen conexión alguna con el objeto del contrato).

Las relaciones interregionales globales llevan la ventaja sobre las bilaterales, ya que el poder negociador en ambos lados, si no es idéntico, es parecido. Así, es posible evitar "jugadas individuales" de países o regiones particulares y hacer más difícil la defensa de intereses nacionales y particulares integrándolos en un instrumento de negociaciones regionales, Las experiencias negativas de América Latina con la integración como región en sus intentos de integración al sistema internacional han producido por cierto una tendencia más acentuada de los estados individuales, especialmente los estados principales, a buscar por sí solos su puesto en la jerarquía internacional. Esto a su vez, no sólo exige mucho más de su capacidad de alianza, sino que limita claramente su poder negociador, por lo menos frente a otros grupos de estados como la Comunidad. Las perspectivas respecto del desarrollo futuro del subsistema en el fondo dan lugar a esperanzas, solamente si el SELA logra establecer una estructura de negociaciones globales entre Améxica Latina y Euro- 
pa Occidental, lo que fortalecería las relaciones internacionales globales.

Por su posición en uno y otro lado del eje Norte-Sur, las desventajas de Europa Occidental muchas veces favorecen a América Latina en la defensa de sus intereses, cosa que en el futuro seguirá caracterizando al subsistema. Por eso, la armonización de intereses seguramente no puede ser objetivo realista de las relaciones interregionales. Al contrario, ciertos obstáculos, como por ejemplo la problemática de la mutua tolerancia frente a sistemas políticos y concepciones de orden económico diferentes, tampoco en el futuro podrán abolirse. Sin embargo, la relación entre Europa Occidental y los Estados socialistas ha demostrado en el último decenio, que armonía en muchas cuestiones políticas no es necesariamente precondición para el buen funcionamiento de un subsistema, especialmente si el subsistema largamente se limita al intercambio económico, y eso probablemente será el caso con el subsistema Europa Occidental-América Latina en los años 80. El funcionamiento solamente ofrece problemas cuando no se está dispuesto a mejorar no sólo la cantidad, sino también la calidad de las relaciones, pues para eso hace falta que las reglas del juego se puedan discutir, y ambos lados tengan conciencia de que sólo juntos son capaces de cambiarlas y asegurar su cumplimiento.

En este análisis de viabilidad de un subsistema, América LatinaEuropa Occidental no se ha tratado con detenimiento el aspecto en las diferentes formas y escalones de la cooperación en los últimos decenios entre otras cosas, porque tal vez aún no existía en el sistema internacional el marco para el funcionamiento de tal subsistema. Todas las relaciones internacionales, sean bilaterales o interregionales, están sujetas a una coyuntura. Por la pérdida relativa de influencia de Europa Occidental y el incremento de prestigio de América Latina en el sistema internacional, los años 80 parecen ofrecer una "buena coyuntura" para el subsistema aquí descrito. Ambas partes aún tendrán que adaptar sus instrumentos y niveles a sus propias exigencias, y a los del otro. Ambos se beneficiarán del hecho de que ya terminaron su fase de "prueba y error". Pero hasta el momento ninguno de los dos ha tenido ni el coraje ni el estilo político con los que fuera posible dejar de lado todos los obstáculos aquí esbozados. 